\title{
Ascaris lumbricoides in the Main Biliary Duct as a Cause of Abdominal Pain in Young Adult
}

\section{William Augusto Casteleins ${ }^{1 *}$, Marcos Roberto Likes Mischiatti², Marlon Rangel $^{3}$ and Rafael William Noda ${ }^{4}$}

\author{
${ }^{1}$ Department of General Surgery, Cajuru University Hospital and Department of \\ Peritoneal Malignancies, Hospital Marcelino Champagnat; Pontifical Catholic \\ University of Paraná, Brazil \\ ${ }^{2}$ Vascular Surgeon and Technical Director at Angiclin, Maringá, Brazil \\ ${ }^{3}$ Department of Gastrointestinal Surgery, Hospital Marcelino Champagnat, Brazil \\ ${ }^{4}$ Department of Digestive Endoscopy, Hospital Marcelino Champagnat; Pontifical \\ Catholic University of Paraná, Brazil
}

*Corresponding Author: William Augusto Casteleins, Department of General Surgery, Cajuru University Hospital and Department of Peritoneal Malignancies, Hospital Marcelino Champagnat; Pontifical Catholic University of Paraná, Brazil.

DOI: $10.31080 /$ ASGIS.2020.03.0122
Received: January 17, 2020

Published: February 17, 2020

(c) All rights are reserved by William Augusto Casteleins., et al.

\begin{abstract}
It is reported a case of ascariasis (roundworm) stuck in the main biliary duct, in a 26 year-old man, presenting in the emergency department with acute abdominal pain, with a few hours from the start, characterized as dyspeptic-like. Complementary initial investigation was unremarkable, with no findings at ultrasound and slight elevation in canalicular enzymes, such as bilirubin (due to unconjugated fraction). During upper digestive endoscopy, the tail of a roundworm was seen coming out of the major duodenal papilla, and the parasite was easily extracted. Abdominal pain was totally resolved after the procedure. We provide a brief discussion of the epidemiological and physiological aspects of Ascaris lumbricoides' infestation in the biliary tree, imaging exams and investigation, treatment options, drug therapy and potential complications.

Keywords: Ascaris lumbricoides; Abdominal Pain; Upper Digestive Endoscopy
\end{abstract}

\section{Abbreviations}

AST: Aspartate Aminotransferase; ALT: Alanine Aminotransferase; ERCP: Endoscopic Retrograde Cholangiopancreatography; MRI: Magnetic Resonance Imaging ( $3 \mathrm{~T}=3$ tesla).

\section{Introduction}

According to the Centers for Disease Control and Prevention (CDC) there are between 807 million to 1.2 billion people in the world infected with Ascaris lumbricoides (also named human roundworm), one type of soil-transmitted helminth [1]. Ascariasis happens when humans and animals ingest the eggs (which is the infective form) of the parasite, that can be found in dirty hands, contaminated soil, vegetables and fruits not carefully cooked, washed or peeled. Therefore, it is a disease directly associated with precarious hygiene and sanitation, but it is also found in places where human stools are utilized as agricultural fertilizer. The global distribution of the infection is in tropical and subtropical areas, where the climate is warm and humid.

The visualization of Ascaris in the biliary tree is a very uncommon finding, although its occurrence might be underdiagnosed around the world, as a cause of abdominal pain, mainly in endemic areas. This is because the worms tend to move constantly in the gastrointestinal tract, hence, getting in and out of the main biliary duct, from which they gain access from the duodenum. Since 1970, a few cases have been reported, most of them from Asia, Africa, South America and some parts of the Middle East [2,3]. Symptoms of ascariasis vary from asymptomatic patients to mild or severe cases of colic, vomiting (sometimes even throwing up live worms), obstruction (due to intraluminal mass of worms), volvulus, and perforation. When Ascaris invades the biliary system, it may cause recurrent cholangitis and pancreatitis, but they may also induce cholecystitis and form biliary calculi containing ova and fragments of adult worms. For this reason, the parasites are usually no longer present in the ducts, at the time of surgery or imaging exams [4].

\section{Case Report}

We present the case of a 26 year-old male patient, who was admitted in the Emergency Room of Cajuru University Hospital, city of Curitiba, Southern region of Brazil, with complaints of acute abdominal pain. It had started suddenly, a few hours prior to admission, and it was dyspeptic-like, located in the epigastrium, irradiated to right upper quadrant, but not to the back, without signs of peritonitis or jaundice. Associated, he complained of nausea and vomiting, loss of appetite and had no fever. Besides, he denied previous diseases, but reported heavy consumption of alcohol (2.5 li- 
ters of distilled beverages per day), smoking habits (10 pack-year) and drugs (cocaine and crack).

Complementary exams were performed; chest x-ray and abdominal ultrasound showed no abnormalities. Laboratory was normal, except for total bilirubin slightly raised $(1.68 \mathrm{mg} / \mathrm{dl}$; normal up to 1.2), due to its indirect fraction (unconjugated) as high as 1.26. Also, liver function enzymes were elevated: alkaline phosphatase $178 \mathrm{U} / \mathrm{L}$ (normal up to 126), gamma-glutamyl transferase 304 U/L (normal up to 73), AST $104 \mathrm{U} / \mathrm{L}$ (normal up to 59), and ALT $459 \mathrm{U} / \mathrm{L}$ (normal up to 72). Amylase and lipase were normal, as well as leukogram $\left(8450 / \mathrm{mm}^{3}\right)$ despite an increase of eosinophils count $\left(10 \%, 845 / \mathrm{mm}^{3}\right.$; normal up to 500$)$. Sorologies were negative for HIV, hepatitis B and C.

Due to the type of pain, the patient underwent upper digestive endoscopy, in which it was identified the tail of a roundworm (Ascaris lumbricoides) at the orifice of the greater duodenal papilla (figure 1). It was easily extracted endoscopically (Figures 2 and 3), and patient improved from pain immediately after the procedure. He was discharged in the following day with a prescription of oral mebendazole.

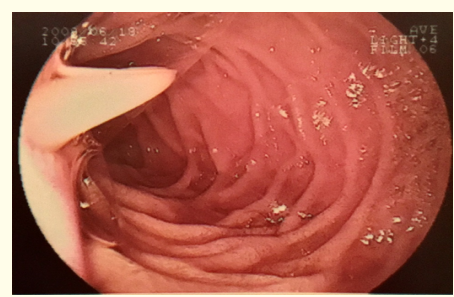

Figure 1: Upper digestive endoscopy showing the extremity of Ascaris lumbricoides (roundworm) out of the greater duodenal papilla.

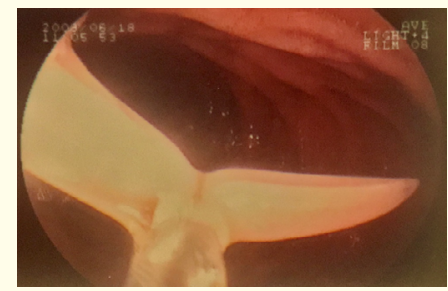

Figure 2: Upper digestive endoscopy removal of roundworm with forceps, from the main biliary duct.

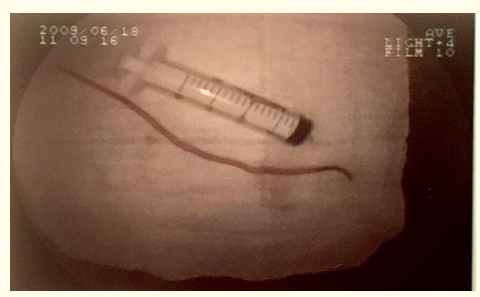

Figure 3: Ascaris lumbricoides extracted from the body, length compared to a 20cc syringe.

\section{Discussion}

Almost $30 \%$ of patients with biliary ascariasis have a prior history of cholecystectomy. It is stated that the dilatation of the main biliary duct, that naturally occurs after the removal of gallbladder, combined with a raise in cholecystokinin, leads to relaxation of the sphincter of Oddi, facilitating the access of the worm to the biliary tree. Other than that, prolonged fasting and endoscopic sphincterotomy is pointed out to be a pre-disposing factor to biliary worm migration in endemic areas [3,5]. Conditions that increase the concentration of progestogens, leading to a physiological relaxation of the smooth muscle (hence, the sphincter) also facilitate the entering of Ascaris in the papilla [5]. Therefore, women (and pregnancy) are more commonly affected than men; in general, children are much less affected than adults, even though ascariasis is more frequent in children. A possible reason for that is the lessen in width of biliary ducts in kids [3].

The majority of cases of ascariasis in the biliary tract are found during surgery for cholecystectomy or exploratory laparotomies, in patients with diagnosis of cholelithiasis or in the context of investigation and treatment of acute abdominal pain [5]. After 1980, it has increased the number of cases diagnosed during endoscopic procedures, such as ERCP. It is remarkable to mention that, prior to the dissemination of endoscopy, there are some reports of roundworms found through oral cholecystography, an exam not so usua nowadays in many centers [2].

Among diagnostic methods, there are different advantages when comparing ultrasound, ERCP, magnetic resonance (MRI) and computed tomography (Table 1), being ultrasound the first exam of choice. Despite its low sensitivity (40-70\%), and operator dependency, it can demonstrate a long and linear structure, corresponding to the worm, without echogenic shadowing, parallel to the axis of the main biliary duct; or else, a hyperechoic moveable tubular pseudotumor (spaghetti sign). Computed tomography tends to be limited, and so, not routinely recommended. ERCP would be the best option for diagnosis and treatment at the same time. MRI, specially enhanced by a 3 tesla system, provides $100 \%$ sensitivity and specificity, although it is expensive and not available in every hospital [5].

The complications of biliary infestation can be due to direct obstruction of the biliary system or to polypeptides secreted by roundworms. This substances cause allergic reactions in the host, leading to spasm of the sphincter of Oddi, what can not only drag the worm into the bile duct, but also carry intestinal bacteria along (such as E. coli, Klebsiella sp., and Pseusomonas aeruginosa). The ambience of stasis may lead to pyogenic cholangitis, cholecystitis, and pancreatitis. If the worm manages to climb the biliary tree into the intrahepatic ducts, it may lead to necrosis and parenchyma abscess [5]. 


\begin{tabular}{|l|c|c|c|c|}
\hline Diagnostic method & Sensitivity & Specificity & Benefits & Disadvantages \\
\hline Ultrasound & $40-70 \%$ & $90 \%$ & $\begin{array}{c}\text { Non-invasive. Fast. } \\
\text { Economical. }\end{array}$ & $\begin{array}{c}\text { Operator dependent, intestinal gas, } \\
\text { limitations in the intrahepatic bile } \\
\text { duct. }\end{array}$ \\
\hline $\begin{array}{l}\text { Endoscopic retrograde } \\
\text { cholangiopancreatography (ERCP) }\end{array}$ & $100 \%$ & $94-95 \%$ & $\begin{array}{c}\text { Diagnostic and } \\
\text { therapeutic. }\end{array}$ & $\begin{array}{c}\text { Has to be done before the parasite } \\
\text { migrates. }\end{array}$ \\
\hline Magnetic resonance cholangiography (3T MRI) & $100 \%$ & $100 \%$ & Non-invasive. & Expensive. Use of advanced technology. \\
\hline Contrasted computed tomography & $54-70 \%$ & $80-90 \%$ & Non-invasive. & \\
\hline
\end{tabular}

Table 1: Diagnostic aids in biliary ascariasis (reproduced from Garcia-Espinoza., et al.) [5].

Malignancy is also documented as a late complication of the disease, although convincing proof of an etiological basis for the association is still needed. Reports of biliary carcinoma occurring after biliary ascariasis are infrequent, however, biliary clonorchiasis and opisthorchiasis have been established as definite risk factors for cholangiocarcinoma [3].

The treatment of biliary ascariasis is based on three pillars: resolving cholangitis and cholecystitis non-operatively, at first; introduce oral anthelminthics, which paralyze the worms and allow them to be naturally eliminated by peristalsis; endoscopic disobstruction of the biliary tree. Nevertheless, simultaneous jaundice and intestinal obstruction, in documented cases of hepato-biliary ascariasis, is usually an indication for surgery. In time, percutaneous needle drainage under ultrasound guidance or even surgically, could be necessary in large hepatic abscesses [6].

The pharmacological options for roundworms are albendazole, levamisole, piperazine citrate, mebendazole, and pyrantel pamoate. The latter two drugs are considered first line, due to the least side effects. Evaluation of the success of treatment can be achieved by stool examination after 1-2 weeks. It is important to note that negative stool samples do not necessarily indicate eradication of the worms. For that reason, preventive drug therapy is recommended in the context of managing helminths, since reinfection is very common in endemic areas [3,5].

\section{Bibliography}

1. https://www.cdc.gov/parasites/ascariasis/index.html

2. Pérez-Machado L., et al. "Ascaris lumbricoides in bile duct: endoscopic and radiologic demonstration by ERCP". Gastrointestinal Endoscopy 29.4 (1983): 329.

3. Sanai FM and Al-Karawi MA. "Biliary ascariasis: report of a complicated case and literature review". Saudi Journal of Gastroenterology 13.1 (2007): 25-32.

4. Khuroo MS and Zargar SA. Biliary ascariasis. A common cause of biliary and pancreatic disease in an endemic area". Gastroenterology 88.2 (1985): 418-23.
5. Garcia-Espinoza JA., et al. "Parasitosis in the bile duct, report of 3 cases and literature review". Revista Médica del Hospital General de México 81.1 (2018): 18-23.

6. Das AK. "Hepatic and biliary ascariasis". Journal of Global Infectious Diseases 6.2 (2014): 65-72.

\section{Assets from publication with us}

- Prompt Acknowledgement after receiving the article

- Thorough Double blinded peer review

- Rapid Publication

- Issue of Publication Certificate

- High visibility of your Published work

Website: www.actascientific.com Submit Article: www.actascientific.com/submission.php Email us: editor@actascientific.com Contact us: +919182824667 